\title{
The Role of Thermal Ablation for Colorectal Liver Metastases in the Era of Effective Chemotherapy
}

\author{
KOSUKE MIMA, TORU BEPPU, TOSHIRO MASUDA, RYU OTAO, \\ KEISUKE MIYAKE, HIROHISA OKABE, AKIRA CHIKAMOTO, \\ NAOKO HAYASHI, TAKATOSHI ISHIKO, \\ HIROSHI TAKAMORI, HIDEO BABA*
}

\begin{abstract}
Department of Gastroenterological Surgery, Graduate School of Medical Sciences, Kumamoto University, 1-1-1 Honjo, Kumamoto 860-8556, Japan
\end{abstract}

\begin{abstract}
After the introduction of new chemotherapeutic agents, including oxaliplatin and irinotecan, chemotherapy can induce tumor down-staging in patients with initially unresectable colorectal liver metastases (CRLM), which thus allows for hepatic resection. Recently, the application of thermal ablation, especially radiofrequency ablation (RFA), has been extended from hepatocellular carcinoma (HCC) to CRLM. However, randomized trials show little evidence to support the clinical efficacy of RFA for CRLM. We herein evaluate the clinical efficacy and the role of thermal ablation for CRLM in this era of effective chemotherapy. Non-randomized retrospective studies have demonstrated the effects of RFA alone for CRLM without new chemotherapeutic agents. The three- and five-year survival rates of RFA alone for CRLM ranged from $42 \%$ to $57 \%$, and $21 \%$ to $37 \%$, respectively. The local recurrence rate was between $9 \%$ and 15\%. In contrast, the five-year survival rates after RFA with perioperative chemotherapy of irinotecan- or oxaliplatin-based regimens ranged from $34 \%$ to $54 \%$. The local recurrence at the site of RFA ranged from $29.7 \%$ to $42.5 \%$. After the introduction of new chemotherapeutic agents, RFA with perioperative chemotherapy of irinotecan- or oxaliplatin-based regimens may improve the survival in patients with CRLM compared to RFA alone. However, the rate of local recurrence of RFA with perioperative chemotherapy was similar to that after RFA alone. The three- and five-year survival rates of RFA in combination with hepatic resection for CRLM ranged from $38 \%$ to $47 \%$, and $47 \%$ to $68 \%$, respectively. The rate of local recurrence at the site of RFA was between 5 and $17.4 \%$, respectively.

In our study, hepatic resection combined with RFA after the FOLFOX regimen resulted in excellent local control rates $(2.5 \%$ recurrence per tumor).

In this era of new and more effective chemotherapy, combining RFA with chemotherapy or hepatic resection for CRLM can extend the indications of surgical resection and further improve patient survival.
\end{abstract}

Key Words: thermal ablation, colorectal liver metastases (CRLM), radiofrequency ablation (RFA),

Received 11 November, 2010, Accepted 14 January, 2011. *Corresponding author; Tel, +81-96-373-5212; Fax, +81-96-371-4378;

e-mail, hdobaba@kumamoto-u.ac.jp

doi : $10.3191 /$ thermalmed.27.1

C 2011 Japanese Society for Thermal Medicine 
perioperative chemotherapy, 5-FU/LV+oxaliplatin (FOLFOX)

\section{Introduction}

Colorectal cancer is the second leading cause of death due to cancer in the United States, and is the third leading cause in Japan ${ }^{1)}$. Colorectal liver metastases (CRLM) are present in approximately 25\% of patients at initial presentation ${ }^{2)}$ and $50 \%$ of patients develop liver metastases during the course of their disease $^{3)}$. The management of patients with CRLM is a therapeutic challenge for both oncologists and surgeons. Surgical resection remains the golden standard for patients with resectable CRLM ${ }^{4}$. Of patients with liver metastases, only $20 \%$ are initially considered resectable ${ }^{5)}$. Combination chemotherapy including modulated infusional 5-fluorouracil (5-FU) plus irinotecan or oxaliplatin can achieve a response rate of $50 \%$ and median survival of over 20 months ${ }^{6-9}$. Oxaliplatain-based chemotherapy, including the FOLFOX regimen, can lead to tumor down-staging in patients with initially unresectable CRLM, and allowed hepatic resection in $16-38 \%$ of patients ${ }^{10-15)}$.

Currently, indications for thermal ablation including microwave coagulation therapy (MCT) and radiofrequency ablation (RFA) have been extended from hepatocellular carcinoma (HCC) to CRLM. However, there is little evidence supporting the routine use of RFA for patients with resectable CRLM because RFA is associated with high local recurrence and poor survival rates compared with conventional liver resection ${ }^{16)}$. However, some studies have reported that hepatic resection combined with local ablation therapy improved hepatic clearance and outcome in patients with CRLM ${ }^{17,18)}$.

In this article, we reviewed the clinical efficacy and the role of RFA for CRLM in the era of new and more effective chemotherapy.

\section{Survival of patients treated by RFA alone for CRLM}

RFA for CRLM has shown various results in non-randomized retrospective studies. Table I showed the 5 independent studies including more than 40 patients treated by RFA alone for CRLM from $2000^{19-23)}$. The three- and five-year survival from the time of diagnosis of liver metastases ranged from $42 \%$ to $57 \%$, and $21 \%$ to $37 \%$, respectively. The local recurrence rate was between $9 \%$ and $15 \%$. Based on these studies, it cannot be concluded whether RFA is an acceptable alternative to resection for resectable CRLM.

Table I. Survival of RFA alone for CRLM

\begin{tabular}{|c|c|c|c|c|c|c|c|}
\hline Author & year & $\begin{array}{l}\text { No. of Patients } \\
\text { with RFA }\end{array}$ & $\begin{array}{l}\text { No. of tumors } \\
\text { per patient }\end{array}$ & $\begin{array}{l}\text { Diameter of } \\
\text { tumors }(\mathrm{cm})\end{array}$ & Approach & $\begin{array}{l}\text { Local recurrence } \\
\text { rate per patient }(\%)\end{array}$ & $\begin{array}{c}\text { Overall survival } \\
\text { rate }(\%)\end{array}$ \\
\hline Elias $^{19)}$ & 2002 & 47 & 1.4 & 2.1 & $\mathrm{P}$ & 11 & NA \\
\hline Abdalla $^{20)}$ & 2004 & 57 & $1-8$ & 2.5 & $\mathrm{O}$ & 9.0 & $21(5 \mathrm{yr})$ \\
\hline Machi $^{21)}$ & 2006 & 100 & 5.1 & 3.0 & $\mathrm{P}, \mathrm{L}, \mathrm{O}$ & NA & $42(3 \mathrm{yr})$ \\
\hline Abitabile $^{22)}$ & 2007 & 47 & 3.1 & 2.4 & $\mathrm{P}, \mathrm{O}$ & NA & 57 (3 yr) \\
\hline $\mathrm{Beppu}^{23)}$ & 2008 & 40 & 2.5 & 2.7 & $\mathrm{P}, \mathrm{L}, \mathrm{O}$ & 15 & 37 (5 yr) \\
\hline
\end{tabular}

RFA, radiofrequency ablation; CRLM, colorectal liver metastases; NA, data not available ; P, percutaneous ;

L, laparoscopic; O, open surgical approach ; yr, year

Only indipendent series with published data including more than 40 patients treated with RFA.

3-, 5-year overall survival was calculated from the time of diagnosis of liver metastases. 


\section{Survival of patients treated by RFA with perioperative chemotherapy for CRLM}

The studies described the number of patients who received chemotherapy and the type of chemotherapeutic regimen were limited. The studies that used RFA with perioperative chemotherapy for CRLM were divided into two groups by the type of chemotherapeutic regimen. The studies that used RFA with perioperative chemotherapy of several regimens during the period of the study were listed in Table II, and the studies that only used perioperative chemotherapy of irinotecan- or oxaliplatin-based regimens were listed in Table III.

Table II showed the 8 studies that used RFA with perioperative chemotherapy of several regimens during the period of the study for CRLM ${ }^{24-31)}$. In these studies, the proportions of patients who received perioperative chemotherapy were between $25 \%$ and $88 \%$. Based on the results of these studies, the threeand five-year survival rates ranged from $20 \%$ to $64 \%$, and $15 \%$ to $30 \%$, respectively. The rate of local recurrence at the site of RFA for CRLM was between 16 and $46 \%$, respectively.

The five-year survival rates after RFA with perioperative chemotherapy of irinotecan- or oxaliplatin-based regimens are available from 4 studies (Table III) ${ }^{32-35}$. In these studies, the proportions of patients who received perioperative chemotherapy of irinotecan- or oxaliplatin-based regimens were between $52.5 \%$ and $100 \%$, and the five-year survival rates ranged from $34 \%$ to $54 \%$. The local

Table II. Survival of RFA with perioperative chemotherapy for CRLM

\begin{tabular}{|c|c|c|c|c|c|c|c|}
\hline Author & year & $\begin{array}{l}\text { No. of Patients } \\
\text { with RFA }\end{array}$ & $\begin{array}{l}\text { No. of tumors } \\
\text { per patient }\end{array}$ & $\begin{array}{l}\text { Diameter of } \\
\text { tumors }(\mathrm{cm})\end{array}$ & $\begin{array}{c}\text { Rates of patients with } \\
\text { chemotherapy }(\%)\end{array}$ & $\begin{array}{l}\text { Local recurrence } \\
\text { rate per patient (\%) }\end{array}$ & $\begin{array}{l}\text { Overall survival } \\
\text { rate }(\%) / \text { MST }\end{array}$ \\
\hline Livraghi $^{24)}$ & 2003 & 88 & $1-3$ & 2.1 & 88 (Pre RFA) & 40 & NA \\
\hline Berber $^{25)}$ & 2005 & 135 & 3.2 & 4.1 & 80 (Pre RFA) & 46 & 44.6 months \\
\hline Siperstein $^{26)}$ & 2007 & 234 & 2.8 & 3.9 & 80 (Pre RFA) & NA & $20(3 \mathrm{yr})$ \\
\hline Sorensen $^{27)}$ & 2007 & 100 & 3.3 & 2.2 & 25 (Pre RFA) & NA & $64(3 \mathrm{yr})$ \\
\hline Berber $^{28)}$ & 2008 & 68 & Solitary & 3.7 & 82 (Pre RFA) & 16 & $30(5 \mathrm{yr})$ \\
\hline Park $^{29)}$ & 2008 & 30 & 1.2 & $\leqq 3$ & 73 (Post RFA) & 23.3 & $15-20(5 \mathrm{yr})$ \\
\hline Veltri ${ }^{30)}$ & 2008 & 122 & 1.6 & 2.9 & 71 (Pre RFA) & 26.3 & $54(3 \mathrm{yr})$ \\
\hline Reuter $^{31)}$ & 2009 & 66 & 2.8 & 3.2 & 67 (Pre RFA) & 17 & $21(5 \mathrm{yr})$ \\
\hline
\end{tabular}

RFA, radiofrequency ablation ; CRLM, colorectal liver metastases; NA, data not available; MST, median survival time ; yr, year Pre RFA, chemotherapy was performed before RFA ; Post RFA, chemotherapy was performed after RFA

3-, 5-year overall survival and median survival time were calculated from the time of diagnosis of liver metastases.

Table III. Survival of RFA with perioperative chemotherapy of irinotecan- or oxaliplatin-based regimens for CRLM

\begin{tabular}{|c|c|c|c|c|c|c|c|c|}
\hline Author & year & $\begin{array}{l}\text { No. of Patients } \\
\text { with RFA }\end{array}$ & $\begin{array}{l}\text { No. of tumors } \\
\text { per patient }\end{array}$ & $\begin{array}{l}\text { Diameter of } \\
\text { tumors }(\mathrm{cm})\end{array}$ & $\begin{array}{l}\text { Rates of patients with } \\
\text { chemotherapy }(\%)\end{array}$ & $\begin{array}{l}\text { No. of Patients received } \\
\text { FOLFOX or FOLFIRI }\end{array}$ & $\begin{array}{l}\text { Local recurrence } \\
\text { rate per patient }(\%)\end{array}$ & $\begin{array}{l}\text { Overall survival } \\
\text { rate }(\%)\end{array}$ \\
\hline $\mathrm{Lee}^{32)}$ & 2008 & 37 & Solitary & $\leqq 3$ & 89 (Post RFA) & $18(54.5 \%)$ & 29.7 & NA \\
\hline Gillams $^{33)}$ & 2008 & 40 & Solitary & 2.3 & 80 (Pre RFA) & $21(52.5 \%)$ & 42.5 & $54(5 \mathrm{yr})$ \\
\hline Gillams $^{34)}$ & 2009 & 309 & 4.0 & 3.7 & 72 (Pre RFA) & $142(59 \%)$ & NA & $34(5 \mathrm{yr})$ \\
\hline Knudsen ${ }^{35)}$ & 2009 & 36 & $1-8$ & 2.1 & 100 (Pre RFA) & $36(100 \%)$ & NA & $34(5 \mathrm{yr})$ \\
\hline
\end{tabular}

RFA, radiofrequency ablation ; CRLM, colorectal liver metastases ; NA, data not available ; yr, year ;

FOLFOX, chemotherapy with folinic acid, 5-fluorouracil, and oxaliplatin; FOLFIRI, chemotherapy with folinic acid, 5-fluorouracil, and irinotecan,

Pre RFA, chemotherapy was performed before RFA; Post RFA, chemotherapy was performed after RFA

3-, 5-year overall survival was calculated from the time of diagnosis of liver metastases. 
recurrence at the site of RFA ranged from $29.7 \%$ to $42.5 \%$. When new chemotherapeutic agents were used, it was possible for RFA with perioperative chemotherapy to improve survival. However, the rate of local recurrence at the site of RFA was similar to that of RFA alone, and larger studies are needed to determine whether there is a significant increase in survival sufficient to be worth the risks of chemotherapy. In a meta-analysis reported by Mulier et $a l^{36}$, factors associated with significantly fewer local recurrences after RFA alone for CRLM included the following: small tumor size, the surgical (open or laparoscopic) approach, location away from large vessels, a $1 \mathrm{~cm}$ intentional margin, and greater physician experience. Berber et al ${ }^{25)}$ reported several predictors of survival in RFA-treated patients with CRLM. In their study, the patients were not candidates for resection, and $80 \%$ had intrahepatic tumor progression despite chemotherapy. The median survival was 28.9 months after RFA, and the local recurrence rate at the site of laparoscopic RFA was $46 \%$. A poor response to chemotherapy prior to RFA may be one of the major risk factors for high local recurrence.

\section{Chemotherapy plus RFA versus chemotherapy alone for CRLM}

The chemotherapy plus local ablation versus chemotherapy (CLOCC) trial was a randomized phase II study conducted by the European Organization for Research and Treatment of Cancer (EORTC). The final results were reported at the American Society of Clinical Oncology $46^{\text {th }}$ Annual Meeting in $2010^{37}$. In the study, 119 patients with unresectable CRLM were randomized to either chemotherapy alone (59 patients) or RFA followed by chemotherapy (60 patients) groups. In both arms, chemotherapy consisted of 6 months of FOLFOX with or without bevacizumab. The maximum tumor size was less than $4 \mathrm{~cm}$, and the median tumor number was 4.0. At a median follow up of 4.4 years, the 30-month overall survival rates were $57.6 \%$ in the chemotherapy alone group and $61.7 \%$ in the RFA plus chemotherapy group, respectively. The median progression free survival was 9.9 months in the chemotherapy alone group and 16.8 months in the RFA plus chemotherapy group. The number of patients with first recurrence at the RFA site only was $5(9 \%)$. The progression free survival therefore significantly improved in the RFA plus chemotherapy group compared to chemotherapy alone group.

\section{Survival of patients treated by RFA in combination with hepatic resection for CRLM}

Table IV showed the 5 studies that used RFA in combination with hepatic resection for

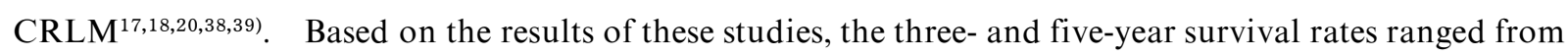
$38 \%$ to $47 \%$, and $47 \%$ to $68 \%$, respectively. The rate of local recurrence at the site of RFA for CRLM was between 5 and $17.4 \%$, respectively.

Table IV. Survival of RFA in combination with hepatic resection for CRLM

\begin{tabular}{lcccccc}
\hline \multicolumn{1}{c}{ Author } & year & $\begin{array}{c}\text { No. of Patients } \\
\text { ith RFA+HR }\end{array}$ & $\begin{array}{c}\text { No. of tumors } \\
\text { per patient }\end{array}$ & $\begin{array}{c}\text { Diameter of } \\
\text { tumors (cm) }\end{array}$ & $\begin{array}{c}\text { Local recurrence } \\
\text { rate per patient (\%) }\end{array}$ & $\begin{array}{c}\text { Overall survival } \\
\text { rate }(\%)\end{array}$ \\
\hline Abdalla $^{20)}$ & 2004 & 101 & NA & NA & 5.0 & $43(3 \mathrm{yr})$ \\
Elias $^{38)}$ & 2005 & 63 & 5.6 & NA & 17.4 & $47(3 \mathrm{yr})$ \\
De Jong $^{39)}$ & 2009 & 134 & $5(1-19)$ & 3.4 & NA & $47.3(5 \mathrm{yr})$ \\
Nikfarjam $^{17)}$ & 2009 & 23 & $2(1-10)$ & 3.0 & NA & $68(5 \mathrm{yr})$ \\
Leung $^{18)}$ & 2010 & 16 & $3(2-7)$ & 2.9 & NA & $38(3 \mathrm{yr})$ \\
\hline
\end{tabular}

RFA, radiofrequency ablation; CRLM, colorectal liver metastases; HR, hepatic resection; NA, data not available ;

3-, 5-year overall survival and median survival time were calculated from the time of diagnosis of liver metastases. 
Traditionally multiple bilobar CRLM were considered unresectable. However, RFA in combination with hepatic resection may be a potential treatment option for patients with multiple bilobar CRLM.

\section{RFA in combination with hepatic resection for CRLM after chemotherapy of FOLFOX in our department}

The determination of the initial resectability of CRLM is based on the possibility of safe and curative (R0) resection. When initially unresectable CRLM became resectable after several courses of FOLFOX, hepatic resection was immediately performed. The final decision to perform surgery after FOLFOX was based on the possibility of removing all metastases by hepatic resection with or without RFA ${ }^{15)}$. Between May 2005 and Dec 2009, 71 patients with initially unresectable CRLM were treated with FOLFOX. Of 71 patients, 26 (37\%) of them were converted to be resectable after chemotherapy using the FOLFOX regimen in our department. Of 26 patients, 8 patients were treated with hepatic resection combined with RFA. Of 40 RFA sites in 8 patients, the median number of RFA sites was 4.5 (range 1-9) and their median diameter was $11 \mathrm{~mm}$ (range 3-25). All patients had bilobar disease. After chemotherapy using FOLFOX for 6 to 8 cycles, 6 patients (75\%) had a partial response, and 2 patients (25\%) had stable disease. Local recurrence at the site of RFA occurred in only one tumor $2.5 \%$ of tumors), as a $2.5 \mathrm{~cm}$ in diameter tumor, during the 30 months of mean observation.

\section{The role of RFA for CRLM in the era of effective chemotherapy}

In the NCCN (National Comprehensive Cancer Network) Clinical Practice Guidelines in Oncology and the guideline of Japanese Society for Cancer of the Colon and Rectum, hepatic resection is the standard of care for the local treatment of initially resectable CRLM ${ }^{40)}$. For patients with initially unresectable CRLM, systemic chemotherapy is the preferred initial treatment. And hepatic resection is recommended for patients with initially unresectable CRLM converted to a potentially curable status following chemotherapy (Fig. 1). However, there is little evidence supporting the use of RFA for patients with CRLM. In the era of new and more effective chemotherapy, the role of RFA for CRLM has not yet been clearly defined.

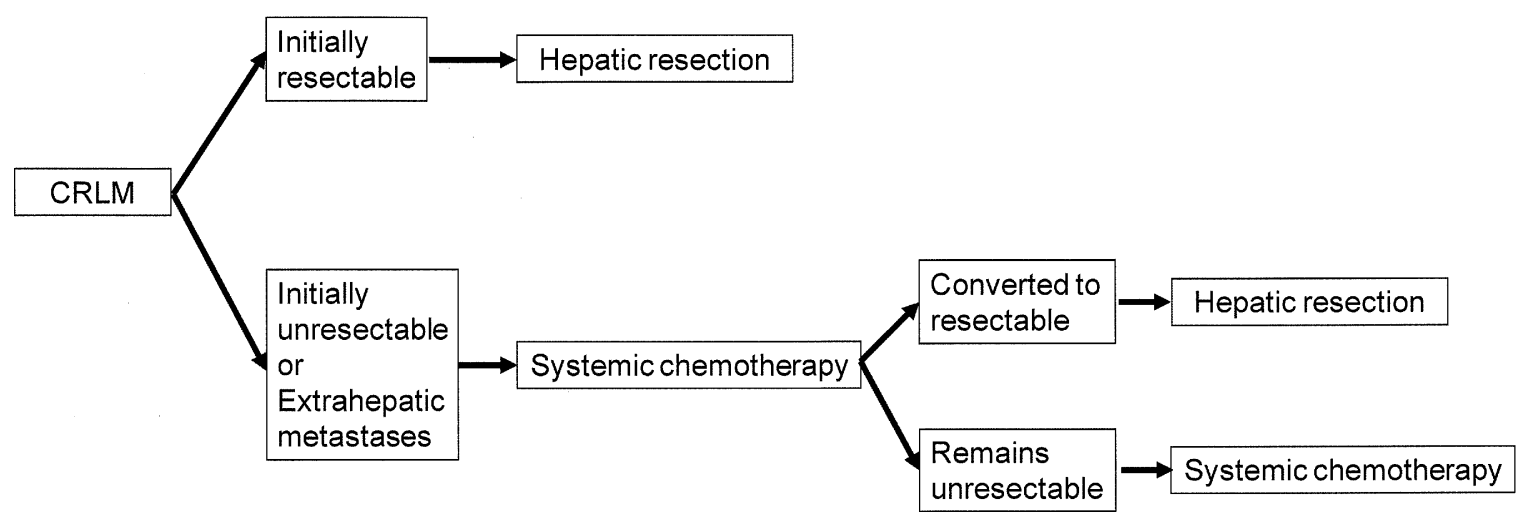

Fig. 1. Therapeutic strategies for colorectal liver metastases 


\section{Conclusions}

At present we cannot conclude whether RFA is an acceptable alternative to hepatic resection for resectable CRLM. Although RFA with perioperative chemotherapy can improve survival, the rate of local recurrence at the site of RFA was similar to that of RFA alone. However, RFA in combination with chemotherapy and hepatic resection for CRLM, especially multiple bilobar CRLM previously considered unresectable, can extend the indications for surgery and improve survival.

\section{Acknowledgements}

This paper was presented at the $5^{\text {th }}$ Asian Congress of Hyperthermic Oncology in Fukuoka, Japan, September, 2010.

\section{References}

1) Kobayashi H., Mochizuki H., Sugihara K., Morita T., Kotake K., Teramoto T., Kameoka S., Saito Y., Takahashi K., Hase K., Oya M., Maeda K., Hirai T., Kameyama M., Shirouzu K., Muto T.: Characteristics of recurrence and surveillance tools after curative resection for colorectal cancer : a multicenter study. Surgery, 141: 67-75, 2007.

2) Mcardle C.S., Hole D.J. : Outcome following surgery for colorectal cancer. Br Med Bull, 64 : 119-125, 2002.

3) Stangl R., Altendorf-Hofmann A., Charnley R.M., Scheele J. : Factors influencing the natural history of colorectal liver metastases. Lancet, 343 : 1405-1410, 1994.

4) Simmonds P.C., Primrose J.N., Colquitt J.L., Garden O.J., Poston G.J., Rees M.: Surgical resection of hepatic metastases from colorectal cancer : a systematic review of published studies. Br J Cancer, 94: 982-999, 2006.

5) Adam R., Delvart V., Pascal G., Valeanu A., Castaing D., Azoulay D., Giacchetti S., Paule B., Kunstlinger F., Ghemard O., Levi F., Bismuth H.: Rescue surgery for unresectable colorectal liver metastases downstaged by chemotherapy: a model to predict long-term survival. Ann Surg, 240: 644-657; discussion 57-58, 2004.

6) De Gramont A., Figer A., Seymour M., Homerin M., Hmissi A., Cassidy J., Boni C., Cortes-Funes H., Cervantes A., Freyer G., Papamichael D., Le Bail N., Louvet C., Hendler D., De Braud F., Wilson C., Morvan F., Bonetti A.: Leucovorin and fluorouracil with or without oxaliplatin as first-line treatment in advanced colorectal cancer. J Clin Oncol, 18 : 2938-2947, 2000.

7) Giacchetti S., Perpoint B., Zidani R., Le Bail N., Faggiuolo R., Focan C., Chollet P., Llory J.F., Letourneau Y., Coudert B., Bertheaut-Cvitkovic F., Larregain-Fournier D., Le Rol A., Walter S., Adam R., Misset J.L., Levi F. : Phase III multicenter randomized trial of oxaliplatin added to chronomodulated fluorouracil-leucovorin as first-line treatment of metastatic colorectal cancer. J Clin Oncol, 18: 136-147, 2000.

8) Goldberg R.M., Sargent D.J., Morton R.F., Fuchs C.S., Ramanathan R.K., Williamson S.K., Findlay B.P., Pitot H.C., Alberts S.R. : A randomized controlled trial of fluorouracil plus leucovorin, irinotecan, and oxaliplatin combinations in patients with previously untreated metastatic colorectal cancer. J Clin Oncol, 22: 23-30, 2004.

9) Grothey A., Sargent D., Goldberg R.M., Schmoll H.J. : Survival of patients with advanced colorectal cancer improves with the availability of fluorouracil-leucovorin, irinotecan, and oxaliplatin in the course of treatment. J Clin Oncol, 22 : 1209-1214, 2004.

10) Falcone A., Ricci S., Brunetti I., Pfanner E., Allegrini G., Barbara C., Crino L., Benedetti G., Evangelista W., Fanchini L., Cortesi E., Picone V., Vitello S., Chiara S., Granetto C., Porcile G., Fioretto L., Orlandini C., Andreuccetti M., Masi G.: Phase III trial of infusional fluorouracil, leucovorin, oxaliplatin, and irinotecan (FOLFOXIRI) compared with infusional fluorouracil, leucovorin, and irinotecan (FOLFIRI) as first-line treatment for metastatic colorectal cancer : the Gruppo Oncologico Nord Ovest. J Clin Oncol, 25: 1670-1676, 2007. 
RFA with chemotherapy and/or HR for CRLM - K. Mima et al.

11) Alberts S.R., Horvath W.L., Sternfeld W.C., Goldberg R.M., Mahoney M.R., Dakhil S.R., Levitt R., Rowland K., Nair S., Sargent D.J., Donohue J.H. : Oxaliplatin, fluorouracil, and leucovorin for patients with unresectable liver-only metastases from colorectal cancer: a North Central Cancer Treatment Group phase II study. J Clin Oncol, 23 : 9243-9249, 2005.

12) Skof E., Rebersek M., Hlebanja Z., Ocvirk J. : Capecitabine plus Irinotecan (XELIRI regimen) compared to 5-FU/LV plus Irinotecan (FOLFIRI regimen) as neoadjuvant treatment for patients with unresectable liver-only metastases of metastatic colorectal cancer : a randomised prospective phase II trial. BMC Cancer, 9: 120, 2009.

13) Van Cutsem E., Rivera F., Berry S., Kretzschmar A., Michael M., Dibartolomeo M., Mazier M.A., Canon J.L., Georgoulias V., Peeters M., Bridgewater J., Cunningham D.: Safety and efficacy of first-line bevacizumab with FOLFOX, XELOX, FOLFIRI and fluoropyrimidines in metastatic colorectal cancer: the BEAT study. Ann Oncol, $20: 1842-1847,2009$.

14) Folprecht G., Gruenberger T., Bechstein W.O., Raab H.R., Lordick F., Hartmann J.T., Lang H., Frilling A., Stoehlmacher J., Weitz J., Konopke R., Stroszczynski C., Liersch T., Ockert D., Herrmann T., Goekkurt E., Parisi F., Kohne C.H.: Tumour response and secondary resectability of colorectal liver metastases following neoadjuvant chemotherapy with cetuximab : the CELIM randomised phase 2 trial. Lancet Oncol, $11: 38-47,2010$.

15) Beppu T., Hayashi N., Masuda T., Komori H., Horino K., Hayashi H., Okabe H., Baba Y., Kinoshita K., Akira C., Watanebe M., Takamori H., Baba H. : FOLFOX enables high resectability and excellent prognosis for initially unresectable colorectal liver metastases. Anticancer Res, 30 : 1015-1020, 2010.

16) Wicherts D.A., De Haas R.J., Adam R. : Bringing unresectable liver disease to resection with curative intent. Eur J Surg Oncol, 33 Suppl 2: S42-S51, 2007.

17) Nikfarjam M., Shereef S., Kimchi E.T., Gusani N.J., Jiang Y., Avella D.M., Mahraj R.P., Staveley-O'carroll K.F.: Survival outcomes of patients with colorectal liver metastases following hepatic resection or ablation in the era of effective chemotherapy. Ann Surg Oncol, 16 : 1860-1867, 2009.

18) Leung E.Y., Roxburgh C.S., Leen E., Horgan P.G. : Combined resection and radiofrequency ablation for bilobar colorectal cancer liver metastases. Hepatogastroenterology, 57: 41-46, 2010.

19) Elias D., De Baere T., Smayra T., Ouellet J.F., Roche A., Lasser P. : Percutaneous radiofrequency thermoablation as an alternative to surgery for treatment of liver tumour recurrence after hepatectomy. Br J Surg, 89: 752-756, 2002.

20) Abdalla E.K., Vauthey J.N., Ellis L.M., Ellis V., Pollock R., Broglio K.R., Hess K., Curley S.A.: Recurrence and outcomes following hepatic resection, radiofrequency ablation, and combined resection/ablation for colorectal liver metastases. Ann Surg, 239 : 818-825; discussion 25-27, 2004.

21) Machi J., Oishi A.J., Sumida K., Sakamoto K., Furumoto N.L., Oishi R.H., Kylstra J.W. : Long-term outcome of radiofrequency ablation for unresectable liver metastases from colorectal cancer : evaluation of prognostic factors and effectiveness in first- and second-line management. Cancer J, 12: 318-326, 2006.

22) Abitabile P., Hartl U., Lange J., Maurer C.A. : Radiofrequency ablation permits an effective treatment for colorectal liver metastasis. Eur J Surg Oncol, 33: 67-71, 2007.

23) Beppu T., Horino K., Komori H., Sugiyama S., Masuda T., Hayashi H., Okabe H., Ohtao R., Imseung C., Hayashi N., Watanabe M., Baba H. : Thermal ablation for colorectal liver metastases. Thermal Med, 24: 83-89, 2008.

24) Livraghi T., Solbiati L., Meloni F., Ierace T., Goldberg S.N., Gazelle G.S. : Percutaneous radiofrequency ablation of liver metastases in potential candidates for resection : the "test-of-time approach". Cancer, 97 : 3027-3035, 2003.

25) Berber E., Pelley R., Siperstein A.E. : Predictors of survival after radiofrequency thermal ablation of colorectal cancer metastases to the liver: a prospective study. J Clin Oncol, 23 : 1358-1364, 2005.

26) Siperstein A.E., Berber E., Ballem N., Parikh R.T.: Survival after radiofrequency ablation of colorectal liver metastases: 10-year experience. Ann Surg, 246 : 559-565; discussion 65-67, 2007.

27) Sorensen S.M., Mortensen F.V., Nielsen D.T. : Radiofrequency ablation of colorectal liver metastases : long-term 
survival. Acta Radiol, 48 : 253-258, 2007.

28) Berber E., Tsinberg M., Tellioglu G., Simpfendorfer C.H., Siperstein A.E.: Resection versus laparoscopic radiofrequency thermal ablation of solitary colorectal liver metastasis. J Gastrointest Surg, 12 : 1967-1972, 2008.

29) Park I.J., Kim H.C., Yu C.S., Kim P.N., Won H.J., Kim J.C. : Radiofrequency ablation for metachronous liver metastasis from colorectal cancer after curative surgery. Ann Surg Oncol, 15 : 227-232, 2008.

30) Veltri A., Sacchetto P., Tosetti I., Pagano E., Fava C., Gandini G. : Radiofrequency ablation of colorectal liver metastases: small size favorably predicts technique effectiveness and survival. Cardiovasc Intervent Radiol, 31: 948-956, 2008.

31) Reuter N.P., Woodall C.E., Scoggins C.R., Mcmasters K.M., Martin R.C. : Radiofrequency ablation vs. resection for hepatic colorectal metastasis : therapeutically equivalent? J Gastrointest Surg, 13: 486-491, 2009.

32) Lee W.S., Yun S.H., Chun H.K., Lee W.Y., Kim S.J., Choi S.H., Heo J.S., Joh J.W., Choi D., Kim S.H., Rhim H., Lim H.K. : Clinical outcomes of hepatic resection and radiofrequency ablation in patients with solitary colorectal liver metastasis. J Clin Gastroenterol, 42: 945-949, 2008.

33) Gillams A.R., Lees W.R. : Five-year survival following radiofrequency ablation of small, solitary, hepatic colorectal metastases. J Vasc Interv Radiol, 19: 712-717, 2008.

34) Gillams A.R., Lees W.R. : Five-year survival in 309 patients with colorectal liver metastases treated with radiofrequency ablation. Eur Radiol, 19: 1206-1213, 2009.

35) Knudsen A.R., Kannerup A.S., Mortensen F.V., Nielsen D.T. : Radiofrequency ablation of colorectal liver metastases downstaged by chemotherapy. Acta Radiol, 50: 716-721, 2009.

36) Mulier S., Ni Y., Jamart J., Ruers T., Marchal G., Michel L.: Local recurrence after hepatic radiofrequency coagulation: multivariate meta-analysis and review of contributing factors. Ann Surg, 242: 158-171, 2005.

37) Ruers T., Punt C.J., van Coevorden F., Borel Rinkes I., Ledermann J.A., Poston G.J., Bechstein W., Lentz M., Mauer M., Nordlinger B. : Final results of the EORTC intergroup randomized study 40004 (CLOCC) evaluating the benefit of radiofrequency ablation (RFA) combined with chemotherapy for unresectable colorectal liver metastases (CRCLM). ASCO Annual Meeting, 2010; abstract No : 3526.

38) Elias D., Baton O., Sideris L., Boige V., Malka D., Liberale G., Pocard M., Lasser P.: Hepatectomy plus intraoperative radiofrequency ablation and chemotherapy to treat technically unresectable multiple colorectal liver metastases. J Surg Oncol, 90 : 36-42, 2005.

39) De Jong M.C., Mayo S.C., Pulitano C., Lanella S., Ribero D., Strub J., Hubert C., Gigot J.F., Schulick R.D., Choti M.A., Aldrighetti L., Mentha G., Capussotti L., Pawlik T.M. : Repeat curative intent liver surgery is safe and effective for recurrent colorectal liver metastasis: results from an international multi-institutional analysis. J Gastrointest Surg, 13 : 2141-2151, 2009.

40) NCCN (National Comprehensive Cancer Network) Clinical Practice Guidelines in Oncology, Colon Cancer V.3. 2009. 